\title{
DELIMITACIÓN DEL ÁMBITO DE LA LEY SUCESORIA Y RÉGIMEN DE EXCLUSIONES DEL REGLAMENTO EUROPEO DE SUCESIONES EN MATERIA DE DERECHOS REALES A LA VISTA DEL PRIMER PRONUNCIAMIENTO INTERPRETATIVO DEL TRIBUNAL DE JUSTICIA DE LA UNIÓN EUROPEA. APROXIMACIÓN AL CERTIFICADO SUCESORIO EUROPEO COMO TÍTULO INSCRIBIBLE EN EL REGISTRO DE LA PROPIEDAD ESPAÑOL
}

Doctorando en Ciencias Económicas, Empresariales y Jurídicas

Universidad de Almería $^{1}$

Email:juanmaj19@hotmail.com

\begin{abstract}
RESUMEN: El 17 de agosto de 2015 marcó el inicio de la aplicabilidad del Reglamento (UE) No 650/2012 del Parlamento Europeo y del Consejo de 4 de julio de 2012, relativo a la competencia, la ley aplicable, el reconocimiento y la ejecución de las resoluciones, a la aceptación y la ejecución de los documentos públicos en materia de sucesiones mortis causa y a la creación de un certificado sucesorio europeo. Dicho Reglamento tiene por objetivo el mantener y desarrollar un espacio de libertad, de seguridad y de justicia, mediante la adopción gradual de medidas dirigidas a la cooperación judicial en asuntos civiles con repercusión transfronteriza, suprimiendo obstáculos a la libre circulación de personas, en particular en aquellos casos en que sea necesario para el buen funcionamiento del mercado interior. A la vista de esta reglamentación, el objetivo de este trabajo se centrará en realizar una aproximación a la articulación de las respuestas a las distintas cuestiones planteadas en el marco del derecho sucesorio con elemento internacional, poniendo el foco en el ámbito de aplicación de este Reglamento, especialmente en la incidencia del régimen de exclusiones en materia de derechos reales previsto por la propia norma y su interpretación por parte del Tribunal de Justicia de la Unión Europea en virtud de la sentencia de 12 de octubre de 2017, asunto C-218/16. Además, se aprovechará la
\end{abstract}

\footnotetext{
${ }^{1}$ Departamento de Derecho Administrativo.
} 
referencia que esta sentencia hace al certificado sucesorio europeo para ponerlo en conexión con su reconocimiento como título sucesorio por parte de nuestra legislación hipotecaria, así como con el control registral del mismo.

PALABRAS CLAVE: Sucesión mortis causa, Reglamento Europeo de Sucesiones, Ámbito de aplicación, Ley aplicable; Derechos Reales, Certificado Sucesorio Europeo, Registro de la Propiedad.

ABSTRACT: On August 17, 2015 began to apply the Regulation (EU) 650/2012 of the European Parliament and of the Council, of July 4, 2012, on jorusdiction, applicable law, recognition and enforcement of decisions and acceptance and enforcement of authentic instruments in matters of succession and on the creation of a European Certificate of Succession. The Regulation es part of the main objective of fostering an area of freedom, security and justice, through the phased adoption of measures leaded to judicial cooperation in civil matters having crossborder implications, particularly removing obstacles to the free movement of personas and contributing to the proper functioning of the internal market. In fact of that, the aim of this paper will be to focus on the articulation of responses to the different questions raised in the context of inheritance law with an international element, focusing on the scope of application of this Regulation, especially in the incidence of the regime of exclusions in the field of real rights provided by the norm itself and its interpretation by the Court of Justice of the European Union by virtue of the judgment of October 12, 2017, case C-218/16. In addition, the reference that this ruling makes to the European Certificate of Succession will be used to put it in connection with its recognition as a succession title by our mortgage legislation, as well as with the land registry control about it.

KEYWORDS: Succession, European private international law, Applicable law, Rights in rem adaptation, European Certificate of Succession, Land Registry.

SUMARIO: I.- Introducción. II.- Asunto C-218/16, Aleksandra Kubicka: primera sentencia del tribunal de justicia de la unión europea interpretando el reglamento europeo de sucesiones. 1 . Antecedentes de hecho y esencia de la cuestión prejudicial planteada. 2. Ley aplicable: universalidad y unidad de la sucesión. 3. Ámbito de aplicación y régimen de exclusiones: Naturaleza de los derechos reales e inscripción de derechos sobre inmuebles en un registro. 4. Reconocimiento y adaptación de derechos reales desconocidos a derechos reales equivalentes en su funcionalidad. III.- Certificado sucesorio europeo y registro de la propiedad. 1. Breve aproximación al concepto de certificado sucesorio europeo. 2. El certificado sucesorio europeo como título inscribible en el Registro de la Propiedad español. 3. Control registral: A) Calificación. B) Inscripción registral. C) Efectos. IV.- Conclusiones. 


\section{I.- INTRODUCCIÓN}

Al amparo de lo previsto en el artículo 81, apartados 1 y 2,c) del Tratado de Funcionamiento de la Unión Europea ${ }^{2}$, puede decirse que la Unión Europea (en adelante, UE) se ha preocupado tradicionalmente por mantener y desarrollar un espacio de libertad, seguridad y justicia que permita y fomente la libre circulación de personas y bienes dentro de su territorio. A este respecto, el propio precepto reconoce que la UE desarrollará una cooperación judicial en asuntos civiles con repercusión transfronteriza, basada en el principio de reconocimiento mutuo de las resoluciones judiciales y extrajudiciales. Esta cooperación podrá incluir la adopción de medidas de aproximación de las disposiciones legales y reglamentarias de los Estados miembros. Adicionalmente, y cuando resulte necesario para el funcionamiento del mercado interior, el Parlamento Europeo y el Consejo deberán adoptar, con arreglo al procedimiento legislativo ordinario, las medidas necesarias para garantizar la compatibilidad de las normas aplicables en los Estados miembros en materia de conflictos de leyes y de jurisdicción.

Por su parte, el artículo 61 del Tratado Constitutivo de la Comunidad Europea ${ }^{3}$, prevé el establecimiento progresivo de un espacio común de libertad, de seguridad y de justicia mediante, entre otras cosas, la adopción de medidas en el ámbito de la cooperación judicial en materia civil. Su artículo 65 menciona expresamente medidas tendentes a "mejorar y simplificar el reconocimiento y la ejecución de resoluciones en asuntos civiles y mercantiles, incluidos los extrajudiciales", así como "fomentar la compatibilidad de las normas aplicables en los Estados miembros sobre conflictos de leyes y de jurisdicción".

En este contexto ${ }^{4}$, el Consejo Europeo reunido en Bruselas los días 4 y 5 de noviembre de 2004, adoptó un programa denominado "Programa de La Haya: Consolidación de la libertad, la seguridad y la Justicia en la Unión Europea", en el cual se subrayó la necesidad de adoptar un instrumento en materia de sucesiones, que abordase en particular las cuestiones de los conflictos de leyes, la competencia, el

\footnotetext{
${ }^{2}$ Versión consolidada publicada en el Diario Oficial de la Unión Europea C 83/50 de 30 de marzo de 2010.

${ }^{3}$ Versión consolidada publicada en el Diario Oficial de las Comunidades Europeas C 325/33 de 21 de diciembre de 2002.

${ }^{4}$ Debe tenerse en cuenta que los diversos instrumentos publicados sobre esta base, y en particular el Reglamento (CE) 44/2001, del Consejo, de 22 de diciembre de 2000, relativo a la competencia judicial, el reconocimiento y ejecución de decisiones en materia civil y mercantil, excluyen las sucesiones de su ámbito de aplicación.
} 
reconocimiento mutuo y la ejecución de las resoluciones en materia de sucesiones y el certificado sucesorio europeo. Todo ello teniendo presente la realidad comunitaria en la materia, fundada en el hecho cierto de las enormes diferencias existentes entre los distintos ordenamientos jurídicos de los Estados miembros en la regulación del fenómeno sucesorio con elemento internacional.

Con este antecedente, aparece el 14 de octubre de 2009 la denominada "Propuesta de Reglamento del Parlamento Europeo y del Consejo relativo a la competencia, la ley aplicable, el reconocimiento y la ejecución de las resoluciones y los actos auténticos en materia de sucesiones y a la creación de un certificado sucesorio europeo" que, en base a principios fundamentales del derecho de la UE propone una regulación uniforme para la materia en el campo del derecho internacional privado con proyección en la ley aplicable, la competencia judicial y de autoridades y los efectos extraterritoriales de decisiones y documentos. Además, se pretende la creación de un título específico de derecho de la UE con vocación de eficacia transfronteriza que acredite las condiciones de heredero, legatario, administrador o ejecutor de la herencia, con asignación en su caso de bienes concretos. El Parlamento Europeo realizó una primera lectura de la Propuesta el 13 de marzo de 2012.

Una vez efectuados los trabajos de elaboración normativa, el día 27 de julio de 2012 se publicó en el Diario Oficial de la Unión Europea (en adelante, DOUE) el Reglamento (UE) 650/2012 del Parlamento Europeo y del Consejo de 4 de julio de 2012, relativo a la competencia, la ley aplicable, el reconocimiento y la ejecución de las resoluciones, a la aceptación y la ejecución de los documentos públicos en matera de sucesiones mortis causa y a la creación de un certificado sucesorio europeo (en adelante, Reglamento Europeo de Sucesiones, RES). Esta norma consta de 83 considerandos en los que se expone su contenido, concretado a lo largo de 84 artículos.

A la vista de esta reglamentación, el objetivo de este trabajo se centrará en realizar una aproximación a la articulación de las respuestas a cuestiones diversas planteadas en el marco del derecho sucesorio con elemento internacional, poniendo el foco en el ámbito de aplicación de este Reglamento y, particularmente, en la incidencia del régimen de exclusiones en materia de derechos reales previsto por la propia norma y su interpretación por parte del Tribunal de Justicia de la Unión Europea (en adelante, 
TJUE), Sala Segunda, en virtud de la sentencia de 12 de octubre de 2017, asunto C218/16 (Kubicka), que es la primera sentencia del TJUE interpretativa del RES, resultando de gran interés práctico, puesto que, como se verá, se centra en el examen de la eficacia real del legado, cuando la ley de situación del inmueble (por contraposición a la ley que rige la sucesión) sólo admite su eficacia obligacional, planteándose como cuestión central la de determinar el alcance de la exclusión material prevista en el RES en relación con la naturaleza de los derechos reales, así como a los requisitos y efectos de su inscripción en un registro. Adicionalmente, y sobre esta base, realizaré una aproximación al concepto de certificado sucesorio europeo como título sucesorio, examinando el respeto a la lex rei sitae en materia de derechos reales y Registro de la Propiedad, tanto en la admisión del numerus clausus a que hace referencia el RES en los derechos reales como en la adaptación de los mismos.

\section{II.- ASUNTO C-218/16, ALEKSANDRA KUBICKA: PRIMERA SENTENCIA DEL TRIBUNAL DE JUSTICIA DE LA UNIÓN EUROPEA INTERPRETANDO EL REGLAMENTO EUROPEO DE SUCESIONES}

\section{Antecedentes de hecho y esencia de la cuestión prejudicial planteada}

Como he señalado anteriormente, la sentencia del TJUE (Sala Segunda), de 12 de octubre de 2017, asunto C-218/16, Aleksandra Kubicka, constituye el primer pronunciamiento interpretativo del RES por parte de dicho Tribunal.

El supuesto de la resolución es el otorgamiento de testamento por parte de la señora Kubicka, de nacionalidad polaca y residente en Alemania, que se dirige a un notario de Polonia para instituir herederos a su esposo (de nacionalidad alemana) y a sus hijos por iguales partes, disponiendo además un legado vindicatorio (permitido por el Derecho polaco) a favor de su marido, sobre su participación en un terreno sobre el que se encuentra construida su vivienda familiar, sita en Alemania (concretamente en Fráncfort del Óder).

En otras palabras, la señora Kubicka desea incluir en su testamento un legado vindicatorio (cuestión controvertida), permitido por el Derecho polaco (ley del Estado 
cuya nacionalidad posee la testadora, y designada por ésta para que rija la totalidad de su sucesión con arreglo a lo previsto en el RES), a favor de su marido, sobre la parte de los derechos de los que ella es titular en el inmueble común sito en Alemania. Respecto al resto de los bienes que integran su patrimonio sucesorio, desea mantener el orden sucesorio legal en virtud del cual su esposo y sus hijos heredan a partes iguales.

El notario polaco, sin embargo, se niega a autorizar el testamento en dichos términos por resultar contrario a la legislación (artículo 2174 BGB) y jurisprudencia alemanas en materia de derechos reales y del Registro de la Propiedad, en cuya virtud se requiere de un contrato celebrado ante notario entre los herederos y el legatario para la transmisión de la propiedad sobre el inmueble, teniendo el legado naturaleza exclusivamente obligacional (legado damnatorio). Y es que en Alemania, los legados vindicatorios extranjeros son objeto de una adaptación, con arreglo al artículo 31 del RES, y pasan a ser legados damnatorios u obligacionales, según resulta de la exposición de motivos de la Ley alemana ${ }^{5}$ que modificó el Derecho interno de conformidad con las disposiciones del RES ${ }^{6}$.

En este sentido, el notario polaco fundamenta su decisión en los artículos 1, apartado 2, letras k) y 1) -que determina su no aplicación-, y 31 del RES -que fundamenta la necesidad de adaptar los derechos reales-, considerando que el legado vindicatorio proyectado debía considerarse como un acto ilícito por contravenir, precisamente, la legislación y la jurisprudencia alemanas.

\footnotetext{
5 Ley sobre los procedimientos internacionales en materia de Derecho sucesorio (Internationales Erbrechtsverfahrensgesetz), de 29 de junio de 2015, según la cual "en cambio, el Derecho alemán no conoce el legado vindicatorio, ni tampoco debe reconocerlo en el marco del RES. Hasta ahora, el Derecho alemán ha procedido a adaptar este legado para transformarlo en un derecho obligacional (legado simple). El artículo 31 del RES no supone ningún cambio en la situación existente".

${ }^{6}$ Según el escrito de conclusiones del Abogado General Sr. Yves Bot, presentadas el 17 de mayo de 2017, para fundamentar que tal legado resulta contrario a la legislación, doctrina y jurisprudencia alemanas relativas a los derechos reales y a la llevanza del registro de la propiedad, el notario emplea los siguientes argumentos (apartado 27): 1) En Derecho alemán sólo se permite el legado simple, que produce efectos obligacionales; 2) Según reiterada jurisprudencia alemana, anterior a la entrada en vigor de este Reglamento, no se reconocen los efectos reales de los legados vindicatorios extranjeros que tienen por objeto un inmueble situado en Alemania, puesto que la ley aplicable a la sucesión no puede determinar la adquisición de derechos sobre tal bien; 3) Así, la inscripción del legatario en el registro de la propiedad solo puede basarse en un contrato celebrado ante notario, relativo a la transmisión de la propiedad sobre el inmueble, entre el heredero y el legatario, en cumplimiento del legado, o bien en una resolución judicial que sustituya a dicho contrato; y 4) Desde la entrada en vigor de dicho Reglamento, estos legados vindicatorios están pasando a ser legados simples, en aplicación del artículo 31 de este mismo Reglamento.
} 
En este caso, la voluntad de la testadora se fundamenta en la expresa exclusión de la utilización del legado obligacional, ya que éste supondría dificultades vinculadas a la representación de sus hijos menores de edad, que en su momento serán llamados a la sucesión, así como gastos adicionales (lo anterior resulta del propio contenido de la sentencia). Es por ello por lo que, con fundamento en el artículo 22 del RES, la señora Kubicka elige la ley del Estado cuya nacionalidad posee en ese momento (Polonia) para que, con arreglo al artículo 23.1 del RES, rija la totalidad de la sucesión.

Tras la desestimación del recurso interpuesto ante el propio notario por la señora Kubicka contra su decisión de denegar el otorgamiento de un testamento que contiene un legado vindicatorio (y en cuya virtud, la señora Kubicka defiende que ninguna de las disposiciones del RES justifica que no se reconozcan los efectos reales del legado vindicatorio, previsto en la ley sucesoria elegida por ella), ésta decide recurrir ante el Tribunal Regional de Gorzów Wielkopolski de Polonia, que a la vista de los hechos y de la documentación aportada, decide suspender el procedimiento y plantear al TJUE la siguiente cuestión prejudicial: ¿Deben interpretarse los artículos 1, apartado 2, letras k) y 1), o 31, del RES en el sentido de que permiten la denegación del reconocimiento de los efectos reales del legado vindicatorio previsto por la ley sucesoria, cuando éste afecta a la propiedad de un inmueble situado en un Estado miembro cuya legislación no reconoce la institución del legado con efectos reales directos?

La cuestión central, como veremos, consiste en determinar el sentido y alcance de la exclusión material prevista en el RES en sus considerandos 15, 18 y 19, así como en su artículo 1, apartado 2, letras k) y 1), y en su artículo 31, relativo a la naturaleza de los derechos reales, así como a los requisitos legales y efectos de su inscripción (o de la falta de inscripción) en un registro, y su posible adaptación. Dicha cuestión debe proyectarse hacia la propia esencia de la previsión contenida en el artículo 23.1 del RES, en este caso delimitada en si el legado de un derecho real (propiedad) que el Estado miembro del lugar de situación del inmueble conoce, debe producir sus efectos respecto del legatario, con independencia del lugar en el que deba ser registrado, puesto que dicho derecho sobre el bien inmueble le ha sido transmitido directamente en virtud de la ley sucesoria (polaca) designada conforme al artículo 22 del RES, cuando la lex rei sitae no reconoce esa modalidad de transmisión. 


\section{Ley aplicable: universalidad y unidad de la sucesión}

La regulación contenida en el RES en el ámbito de la ley aplicable se asienta sobre la base de dos principios fundamentales: de un lado, el de aplicación universal, en cuya virtud la ley se aplicará aún cuando no sea la de un estado miembro; y el de unidad de la sucesión, en virtud del cual habrá una sola ley aplicable a la sucesión, con independencia de la naturaleza de los bienes y del lugar donde se hallen.

El denominado principio de universalidad se recoge en el artículo 20 del RES, el cual establece que la ley designada por dicho Reglamento se aplicará aun cuando no sea la de un estado miembro.

Por su parte, el principio de unidad de la sucesión aparece en el apartado 1 del artículo 23 del RES, que establece que la ley determinada regirá la totalidad de la sucesión. Se justifica este principio en razones de seguridad jurídica y en evitar la fragmentación de la sucesión, por lo que, tal y como establece el considerando 37 del RES, "es necesario que esta ley rija la totalidad de la sucesión, es decir, todos los bienes y derechos, con independencia de su naturaleza y de si están ubicados en otros Estado miembro o en un tercer Estado, que formen parte de la herencia".

No obstante, este principio de unidad de la sucesión presente alguna que otra excepción. Así, por ejemplo, el artículo 30 del propio RES admite que cuando la ley del Estado donde estén sitos los inmuebles, empresas u otras categorías especiales de bienes contenga disposiciones que, por razones de índole económica, familiar o social, impongan restricciones a la sucesión de dichos bienes, tales disposiciones se apliquen a la sucesión en la medida a su vez en que, en virtud del Derecho del Estado miembro, sean aplicables con independencia de la ley que rija la sucesión.

Por último, la ley determinada como aplicable a la sucesión debe regir ésta "desde la apertura de la misma hasta la transmisión a los beneficiarios de la propiedad de los bienes y derechos que integren la herencia" (considerando 42 del RES).

Sentado lo anterior, procede señalar que los artículos 21 y 22 del RES se refieren en particular a la ley aplicable a la sucesión, y lo hacen sobre la base del establecimiento de una regla general (residencia habitual del causante en el momento del fallecimiento) 
y dos excepciones (vinculo más estrecho y posibilidad de elección de la ley aplicable a la sucesión por parte del causante).

Así, dispone el artículo 21.1 del RES que "salvo disposición contraria del presente Reglamento, la ley aplicable a la totalidad de la sucesión será la del Estado en el que el causante tuviera su residencia habitual en el momento del fallecimiento". El punto de conexión residencia habitual del causante presenta un carácter flexible, y es que resulta evidente que cambiar de residencia habitual es mucho más sencillo que hacerlo de nacionalidad. De este modo, este punto de conexión conlleva que una persona puede cambiar la Ley aplicable a su sucesión mediante un simple cambio de su residencia habitual. En tal sentido, algún autor ha afirmado que el artículo 21.1 del RES favorece la libertad testamentaria y la libre disposición de su patrimonio por actos jurídicos mortis causa, ya que el causante puede elegir un país concreto donde exista tal libertad testamentaria y situar en dicho Estado su residencia habitual ${ }^{7}$.

La residencia habitual constituye un punto de conexión innovador para la mayor parte de los Estados miembros de la UE, incluyendo a España, ya que la norma de conflicto española (artículo 9.8 del Código $\mathrm{Civil}^{8}$ ) se basa en el criterio de la última nacionalidad del causante.

Adicionalmente, y como se ha visto, el artículo 21.1 del RES sólo tiene en cuenta la residencia habitual del causante en el momento del fallecimiento, lo que supone que se evite el tema del conflicto móvil y se aporte certeza legal a la solución. Ahora bien, resulta sumamente criticable la falta de definición legal de lo que debe entenderse por residencia habitual a efectos de dicho RES ${ }^{9}$. El considerando 23 del RES

\footnotetext{
${ }^{7}$ Así, CARRASCOSA GONZÁLEZ, J. "Reglamento sucesorio europeo y residencia habitual del causante". Cuadernos de Derecho Transnacional, marzo 2016, vol. 8, núm. 1, p. 54.

8 "La sucesión por causa de muerte se regirá por la ley nacional del causante en el momento de su fallecimiento, cualesquiera que sean la naturaleza de los bienes y el país donde se encuentren. Sin embargo, las disposiciones hechas en testamento y los pactos sucesorios ordenados conforme a la ley nacional del testador o del disponente en el momento de su otorgamiento conservarán su validez aunque sea otra la ley que rija la sucesión, si bien las legítimas se ajustarán, en su caso, a esta última. Los derechos que por ministerio de la Ley se atribuyan al cónyuge supérstite se regirán por la misma ley que regule los efectos del matrimonio, a salvo siempre las legítimas de los descendientes". Este apartado fue redactado por la Ley 11/1990, de 15 de octubre, de reforma del Código Civil (B.O.E. de 18 de octubre).

9 Sobre esta cuestión, vid. CALVO VIDAL, I. "El Derecho de sucesiones en la Unión Europea. Ley aplicable y carácter universal de la nueva normativa en materia de sucesiones". Noticias de la UE, núm. 328, 2012, pp. 97-107, quien explica cómo el Consejo del Notariado de la UE aconsejaba mediante su "toma de posición" de 24 de noviembre de 2010, no definir en el texto legal el concepto de residencia habitual para no encapsular la rica realidad sucesoria y ofrecer, en cambio, a los tribunales y autoridades, en los Considerandos del RES ciertos elementos a modo de "guía de localización de la residencia habitual".
} 
prevé, con el fin de determinar la residencia habitual del causante, que la autoridad que sustancie la sucesión proceda a realizar una evaluación general de las circunstancias de la vida del causante durante los años precedentes a su fallecimiento y en el momento del mismo, tomando en consideración todos los hechos pertinentes, en particular la duración y la regularidad de la presencia del causante en el Estado de que se trate, así como las condiciones y los motivos de dicha presencia. La residencia habitual así determinada debería revelar un vínculo estrecho y estable con el Estado de que se trate, teniendo en cuenta los objetivos específicos del RES.

Ahora bien, el propio RES reconoce que, en algunos supuestos, determinar la residencia habitual del causante puede resultar complejo. "Tal será el caso, en particular, cuando por motivos profesionales o económicos el causante hubiese trasladado su domicilio a otro país para trabajar en él, a veces por un periodo prolongado, pero hubiera mantenido un vínculo estrecho y estable con su Estado de origen. En tal caso, dependiendo de las circunstancias, podría considerarse que el causante tenía su residencia habitual en su Estado de origen, en el que estaba situado el centro de interés de su familia y su vida social. También podrían suscitarse otras situaciones complejas cuando el causante haya residido en diversos Estados alternativamente o viajado de un Estado a otro sin residir permanentemente en ninguno de ellos. Si el causante fuera nacional de uno de dichos Estados o tuviera sus principales bienes en uno de ellos, la nacionalidad de aquel o la localización de dichos bienes podrían constituir un factor especial en la evaluación general de todas las circunstancias objetivas" (considerando 24 del RES).

Como he señalado anteriormente, el punto de conexión objetivo basado en la residencia habitual del causante en el momento del fallecimiento, se encuentra modulado por dos factores. A saber: la cláusula de excepción basada en el vínculo más estrecho (artículo 21.2 del RES) y la posibilidad de elección de la ley aplicable a la sucesión por parte del causante (artículo 22 del RES).

Por lo que respecta al supuesto de vínculo manifiestamente más estrecho del causante con un Estado distinto del Estado cuya ley fuese aplicable de conformidad con el punto de conexión "residencia habitual", debe decirse que el Reglamento proporciona de este modo una solución a los supuestos excepcionales contemplados en sus considerandos 24 y 25. Es decir, casos de personas que por motivos profesionales o 
económicos estuviesen trabajando en un Estado distinto al de origen, pero con el que mantienen contactos frecuentes, estrechos y continuados. En tal supuesto, dependiendo de las circunstancias, se puede o bien considerar que el causante tenía la residencia habitual en el Estado de origen, en el que se encontraba situado su centro de interés familiar y social, o bien ante la duda y por la operatividad de esta excepción planteada, se podría aplicar la norma del Estado con el que tiene el vínculo más estrecho precisamente en base a ello y siempre que el mismo resultara acreditado.

Esencial para la aplicabilidad de esta excepción resulta el supuesto planteado en el considerando 25 del RES, igualmente basado en el caso excepcional en el que el causante se haya mudado al Estado de su residencia habitual poco tiempo antes de su fallecimiento, siempre que todas las circunstancias del caso indiquen que aquel tenía un vínculo manifiestamente más estrecho con otro Estado. En tal caso, la autoridad que sustancie la sucesión podría llegar a concluir que la ley aplicable a la sucesión no sea la ley del Estado de residencia habitual del causante sino la ley del Estado con el que el causante tenía un vínculo manifiestamente más estrecho. No obstante, la vinculación manifiestamente más estrecha no debe emplearse como nexo subsidiario cuando la determinación de la residencia habitual del causante en el momento de su fallecimiento resulte compleja ${ }^{10}$.

El segundo factor de flexibilización es la posibilidad de elección de la ley aplicable a la sucesión por parte del causante (professio iuris), lo que tiene por objeto permitir la planificación de la sucesión. El artículo 22 del RES limita dicha posibilidad de elección a la "ley del Estado cuya nacionalidad posea" la persona en el momento de realizar la elección o bien en el momento del fallecimiento. Para el caso de que esa persona posea varias nacionalidades, la propia norma prevé la posibilidad de elegir la ley de cualquiera de los Estados cuya nacionalidad posea en el momento de realizar la elección o en el momento del fallecimiento.

Para la operatividad efectiva de este segundo factor de flexibilización, se requiere que la elección se haga expresamente ${ }^{11}$ en forma de disposición mortis causa,

\footnotetext{
${ }^{10}$ PUIG BLANES, F. "Cuestiones esenciales que plantea en la práctica el Reglamento 650/2012 con especial referencia al Derecho Interregional", XXV Encuentros del Foro Aragonés, p. 147.

${ }^{11}$ La Dirección General de los Registros y del Notariado, en Resolución de 10 de abril de 2017 (B.O.E. Núm. 99, de 26 de abril) precisa que "sólo de resultar una professio iuris expresa o indubitada en sus términos, dicha elección, conforme al artículo 22 del RES, implicaría la regulación de la validez material por la ley elegida".
} 
admitiéndose no obstante la posibilidad de que resulte de los términos de una disposición de ese tipo (elección tácita). En desarrollo de esta cuestión, el considerando 39 del RES precisa que "puede considerarse que la elección de la ley resulta de una disposición mortis causa en caso de que, por ejemplo, el causante haya hecho referencia en ella a determinadas disposiciones específicas de la ley del Estado de su nacionalidad o haya mencionado explícitamente de otro modo esa ley".

Una vez expuesto lo anterior, podemos observar cómo en el supuesto de hecho de la sentencia del TJUE, asunto C-218/16, que nos ocupa, la señora Kubicka, "nacional polaca residente en Alemania", en ejercicio estricto de la facultad de elección reconocida por el citado artículo 22 del RES, se dirige a un notario polaco para otorgar testamento con arreglo al Derecho del país de su nacionalidad "en el momento de realizar la elección" (artículo 22.1 del RES). La particularidad del caso viene determinada por la intención de la señora Kubicka de ordenar un legado vindicatorio (con eficacia real, permitido por el Derecho polaco) a favor de su marido, sobre su participación en la vivienda familiar, la cual se encuentra situada en Alemania, tal y como ya se ha expuesto. $\mathrm{Y}$ es que a juicio del notario polaco al que se dirige, dicho legado resulta contrario a la legislación y jurisprudencia alemanas, que requieren de un contrato celebrado ante notario entre los herederos y el legatario para la transmisión de la propiedad sobre el inmueble, tendiendo el legado naturaleza exclusivamente obligacional. Sin embargo, la elección de la ley aplicable a la sucesión de la señora Kubicka resulta, tal y como se ha expuesto, totalmente ajustada a lo previsto por el RES. En consecuencia, esta cuestión no resulta controvertida.

Así lo reconoce el propio TJUE en los apartados 42, 43 y 44 de la sentencia que nos ocupa. En primer lugar, declara acreditado que los hechos del procedimiento principal conciernen a una sucesión testamentaria. Seguidamente, precisa que del tenor del artículo 22, apartado 1, del RES, se desprende que el testador podrá designar la ley del Estado cuya nacionalidad posea como ley que regirá la totalidad de la sucesión; consagrando dicho Reglamento, en su artículo 23, apartado 1, el principio de unidad de la ley aplicable a la sucesión. Para finalizar, declara que dicha ley regirá, en particular, la transmisión a los herederos y, en su caso, a los legatarios de los bienes que integren la herencia, con fundamento en el apartado 2 del artículo 23 del RES. 


\section{3. Ámbito de aplicación y régimen de exclusiones: Naturaleza de los derechos reales e inscripción de derechos sobre inmuebles en un registro}

Cuando nos referimos al ámbito de aplicación del RES, lo hacemos desde una óptica triple: espacial, temporal y material, incidiendo, a los efectos del presente trabajo, en este último ámbito.

Por lo que respecta al ámbito de aplicación espacial, hay que decir que el RES se aplica en todos los Estados miembros de la UE, a excepción de Dinamarca, Reino Unido e Irlanda (si bien estos dos últimos Estados podrán optar por incorporarse al mismo de conformidad con el Protocolo 21 que acompaña al Tratado de Lisboa sobre la posición de Reino Unido e Irlanda, respecto del espacio de libertad, seguridad y justicia).

En cuanto a su relación con otros convenios internacionales vigentes, según el artículo 75 del RES, dicho Reglamento "no afectará a la aplicación de los convenios internacionales de los que sean parte uno o más Estados miembros en el momento de la adopción del presente Reglamento y que se refieran a materias reguladas por él". No obstante, el mismo precepto aclara que, por lo que respecta a las relaciones entre los Estados miembros, "el presente Reglamento primará frente a los convenios celebrados exclusivamente entre dos o más Estados miembros en la medida en que dichos convenios versen sobre las materias reguladas por el presente Reglamento".

En cuanto a su ámbito de aplicación temporal, y de conformidad con el artículo 84 del RES, será aplicable a partir del 17 de agosto de 2015, excepto por lo que respecta a los artículos 77 y 78 (información facilitada al público e información sobre datos de contacto y procedimientos), aplicables a partir del 16 de enero de 2014, y a los artículos 79 (establecimiento y modificación posterior de la lista con la información a que se refiere el artículo 3, apartado 2), 80 (establecimiento y modificación posterior de las certificaciones y los formularios a que se refieren los artículos 46, 59, 60, 61, 65 y 67) y 81 (procedimiento de comité), aplicables a partir del 5 de julio de 2012.

Y en cuanto a su ámbito de aplicación material, establece el considerando 9 del RES que el ámbito de aplicación de dicho Reglamento debe abarcar todos los aspectos de Derecho Civil de la sucesión por causa de muerte, es decir, cualquier forma de transmisión de bienes, derechos y obligaciones por causa de muerte, ya derive de una 
transmisión voluntaria en virtud de una disposición mortis causa, ya de una transmisión abintestato. Ahora bien, el RES no se aplicará a cuestiones fiscales ni a cuestiones administrativas de Derecho público (considerando 10). Tampoco se aplicará a ámbitos del Derecho civil distintos de la sucesión (considerando 11).

El artículo 1 del RES se refiere expresamente al ámbito de aplicación material del mismo, estructurándose en torno a dos apartados:

- Según el apartado 1 de dicho artículo, el RES se aplicará a las sucesiones por causa de muerte, y no será aplicable a las cuestiones fiscales, aduaneras y administrativas (ciñéndose, de este modo, al contenido de los considerandos 9 y 10 anteriormente citados).

- Por su parte, el apartado 2 contiene una enumeración de materias que expresamente quedan fuera del ámbito de aplicación del RES. Son las siguientes:

a) El estado civil de las personas, así como las relaciones familiares y las relaciones que, con arreglo a la ley aplicable a las mismas, tengan efectos comparables.

b) La capacidad jurídica de las personas físicas, sin perjuicio de lo dispuesto en el artículo 23, apartado 2, letra c) y en el artículo 26.

c) Las cuestiones relativas a la desaparición, la ausencia o la presunción de muerte de una persona física.

d) Las cuestiones relativas a los regímenes económicos matrimoniales, así como a los regímenes patrimoniales resultantes de las relaciones que la ley aplicable a las mismas considere que tienen efectos comparables al matrimonio.

e) Las obligaciones de alimentos distintas de las que tengan su causa en la muerte.

f) La validez formal de las disposiciones mortis causa hechas oralmente. 
g) Los bienes, derechos y acciones creados o transmitidos por título distinto de la sucesión, por ejemplo, mediante liberalidades, propiedad conjunta de varias personas con reversión a favor del supérstite, planes de pensiones, contratos de seguros y transacciones de naturaleza análoga, sin perjuicio de lo dispuesto en el artículo 23, apartado 2, letra i).

h) Las cuestiones que se rijan por la normativa aplicable a las sociedades, asociaciones y otras personas jurídicas, como las cláusulas contenidas en las escrituras fundacionales y en los estatutos de sociedades, asociaciones y otras personas jurídicas, que especifican la suerte de las participaciones sociales a la muerte de sus miembros.

i) La disolución, extinción y fusión de sociedades, asociaciones y otras personas jurídicas.

j) La creación, administración y disolución de trusts.

k) La naturaleza de los derechos reales.

1) Cualquier inscripción de derechos sobre bienes muebles o inmuebles en un registro, incluidos los requisitos legales para la práctica de los asientos, y los efectos de la inscripción o de la omisión de inscripción de tales derechos en el mismo.

A los efectos del presente trabajo, me centraré en los supuestos de exclusión k) y 1), por resultar integrados en la cuestión prejudicial planteada al TJUE, a la que se da respuesta en la Sentencia que ahora nos ocupa ${ }^{12}$.

Por lo que respecta, en primer lugar, a la cuestión de si el artículo 1, apartado 2, letra k), del RES debe interpretarse en el sentido de que se opone a la denegación del reconocimiento en Alemania de los efectos reales del legado vindicatorio previsto por el Derecho polaco, ha de observarse, a juicio del Tribunal, que dicha disposición

\footnotetext{
${ }^{12}$ Sobre este particular, RODRÍGUEZ SÁNCHEZ, J.S. "Una introducción al Reglamento de Sucesiones de la UE -desde la perspectiva de los derechos reales sobre bienes inmuebles y el Registro de la Propiedad en España-". Cuadernos de Derecho Registral, Colegio de Registradores de la Propiedad y Mercantiles de España, Madrid, 2013, p. 112, señala que "las exclusiones previstas en las letras k) y l) en relación con la naturaleza de los derechos reales y su publicidad representan una de las cuestiones claves del Reglamento en cuanto definen el marco general en la relación entre lex successionis y lex rei sitae".
} 
lo que excluye en realidad del ámbito de aplicación del RES es "la naturaleza de los derechos reales".

A la exclusión de la naturaleza de los derechos reales se refiere el considerando 15 del RES, que admite la posibilidad de creación o la transmisión mediante sucesión de un derecho sobre bienes muebles e inmuebles tal como prevea la ley aplicable a la sucesión. No obstante, no debe afectar al número limitado (numerus clausus) de derechos reales reconocidos en el ordenamiento jurídico de algunos Estados miembros. En consecuencia, no se debe exigir a un Estado miembro que reconozca un derecho real relativo a bienes ubicados en ese Estado miembro si su ordenamiento jurídico desconoce ese derecho.

Resulta clave en este punto lo que el Abogado General, Sr. Yves Bot, recoge en su escrito de conclusiones de 17 de mayo de 2017, en el cual afirma con rotundidad que, a través del legado vindicatorio, lo que la señora Kubicka pretende es "atribuir al legatario su participación en la plena propiedad de un bien, esto es, un derecho real (propiedad) conocido en los dos sistemas jurídicos afectados, con arreglo a su titularidad actual" (apartado 46). En consecuencia, "la elección de un legado vindicatorio en lugar de un legado simple no modifica, pues, el contenido del derecho que se ejercerá sobre el bien. Se limita a organizar la transmisión directa de un derecho real, en lugar de una transmisión indirecta mediante la creación de un derecho personal en beneficio del legatario" (apartado 47).

Es decir, el Sr. Yves Bot incide en el hecho de que la exclusión prevista en el artículo 1, apartado 2, letra k) del RES no tiene por objeto esta divergencia en la modalidad de transmisión (directa o indirecta) del derecho real, a diferencia de lo que sostiene el Gobierno alemán. En efecto, únicamente la determinación de la naturaleza y del número de derechos reales debe seguir siendo competencia de la ley de situación del inmueble, tal y como precisa con total claridad el precitado considerando 15 del RES.

En esta línea argumental se mueve el TJUE en la sentencia que nos ocupa, al reconocer que "en el presente asunto, tanto el legado vindicatorio, previsto por el Derecho polaco, como el legado damnatorio u obligacional, previsto por el Derecho alemán, constituyen modalidades de transmisión de la propiedad de un bien, esto es, un derecho real reconocido en los dos sistemas jurídicos afectados. De este modo, la 
transmisión directa de un derecho de propiedad mediante un legado vindicatorio sólo afecta a las modalidades de transmisión de ese derecho real al fallecer el testador, transmisión que, según su considerando 15, justamente el RES permite de conformidad con la ley aplicable a la sucesión" (apartado 49). Para concluir que, "tales modalidades de transmisión no están comprendidas" en el ámbito de aquella exclusión.

Por consiguiente, a juicio del TJUE, "ha de considerarse que el artículo 1, apartado 2, letra k) del RES debe interpretarse en el sentido de que se opone a la denegación del reconocimiento, en Estado miembro cuyo ordenamiento jurídico no reconoce la institución del legado vindicatorio, de los efectos reales producidos por dicho legado en la fecha de apertura de la sucesión con arreglo a la ley sucesoria elegida por el testador" (apartado 51). Y es que resulta evidente, en definitiva, que la naturaleza del derecho real (que es el de propiedad) no se discute, ya que tal derecho se encuentra reconocido por los dos sistemas jurídicos afectados. En consecuencia, no opera la exclusión invocada.

Y dado que la naturaleza del derecho real no se discute, pues como se ha dicho consta que tanto el Derecho alemán como el polaco reconocen el derecho de propiedad transmitido en virtud del legado vindicatorio, no sería preciso, a juicio del TJUE (apartado 64 de la sentencia) llevar a cabo la adaptación prevista en el artículo 31 del RES, en cuya virtud "cuando una persona invoque un derecho real que le corresponda en virtud de la ley aplicable a la sucesión y el Derecho del Estado miembro en el que lo invoque no conozca ese derecho real en cuestión, este deberá, en caso necesario y en la medida de lo posible, ser adaptado al derecho real equivalente más cercano del Derecho de ese Estado, teniendo en cuenta los objetivos y los intereses que aquel derecho real persiga y los efectos inherentes al mismo". Obviamente, este precepto no trata de las modalidades de transmisión de los derechos reales, modalidades entre las que, en el presente caso, cabría incluir en particular el legado vindicatorio y el legado damnatorio u obligacional, sino que versa únicamente sobre el respeto del contenido de los derechos reales, determinado por la ley aplicable a la sucesión (lex causae) y sobre su recepción en el ordenamiento jurídico del Estado miembro en el que se invocan (lex rei sitae).

Por lo que respecta a lo que podríamos denominar exclusión del sistema de registro, según resulta del artículo 1, apartado 2, letra k) del RES, debemos remitirnos 
inicialmente al contenido de los considerandos 18 y 19 de dicho Reglamento. Y es que los requisitos de la inscripción en un registro de un derecho sobre bienes muebles o inmuebles se deben excluir del ámbito de aplicación del RES. En este sentido, debe ser el Derecho del Estado miembro en el que esté situado el registro (para el caso de los bienes inmuebles, donde radique el bien) el que determine en qué condiciones legales y de qué manera se realiza la inscripción, así como qué autoridades, como registradores de la propiedad o notarios, se ocupan de verificar que se reúnen todos los requisitos y que la documentación presentada es suficiente o contiene la información necesaria.

En particular, las autoridades podrán comprobar que el derecho del causante sobre los bienes sucesorios mencionados en el documento presentado para su inscripción es un derecho inscrito como tal en el registro o un derecho que de otro modo se haya probado que es conforme con el ordenamiento jurídico del Estado miembro en que esté situado el registro ${ }^{13}$.

Se deben excluir también del ámbito de aplicación del RES los efectos de la inscripción de los derechos en el registro. En consecuencia, debe corresponder al Derecho del Estado miembro en que esté situado el registro determinar si la inscripción tiene, por ejemplo, efecto declarativo o constitutivo. Así pues, en caso de que, por ejemplo, la adquisición de un derecho sobre un bien inmueble deba ser inscrita con arreglo al Derecho del Estado miembro en que esté situado el registro para producir efectos erga omnes o para la protección legal del negocio jurídico, el momento de dicha adquisición deberá regirse por el Derecho de este Estado miembro.

A juicio del Abogado General, Sr. Yves Bot, no es posible en todos los casos convertir el requisito de la inscripción en una condición de la adquisición del derecho real. En efecto, esta reserva debe combinarse necesariamente con el principio de unidad de la ley sucesoria, previsto en el artículo 23, apartado 2, letra e) del RES, según el cual la ley sucesoria regirá "la transmisión a los herederos y a los legatarios de los bienes, derechos y obligaciones". Y es que una interpretación distinta reduciría de forma considerable el

13 En este contexto, vid. BONOMI, A. y WAUTELET, P. "Le droit européen des succession, Commentaire du règlement (UE) $n^{\circ}$ 650/2012, du 4 juillet 2012". Bruylant, Bruselas, 2016, puntos 125130, pp. 135 a 137, que en relación con los requisitos legales establecidos en el considerando 18 del RES, relativos, entre otras cosas, al plazo de inscripción y a los requisitos formales, están destinados a garantizar la seguridad inherente a toda forma de registro de transmisión de derechos. 
alcance de este principio, mientras que debe tenerse en cuenta el objetivo perseguido por el legislador comunitario (apartado 60 de su escrito de conclusiones).

$\mathrm{Y}$ es precisamente esta argumentación del Abogado General la que toma en consideración el TJUE, que a la vista del contenido de los considerandos 18 y 19 del RES deduce, tal y "como el Abogado General ha señalado sustancialmente en el punto 60 de sus conclusiones, que puesto que el artículo 1, apartado 2, letra 1) del RES sólo se refiere a la inscripción de derechos sobre bienes muebles o inmuebles en un registro, incluidos los requisitos legales para la práctica de los asientos, y a los efectos de la inscripción o de la omisión de inscripción de tales derechos en el mismo, los requisitos para la adquisición de tales derechos no figuran entre las materias excluidas del ámbito de aplicación de dicho Reglamento en virtud de la citada disposición" (apartado 54 de la sentencia).

A juicio del TJUE, dicha interpretación aparece confirmada por el principio de unidad de la ley sucesoria (tal y como el Abogado General defiende en su escrito de conclusiones), previsto en el artículo 23 del RES, y especialmente en su apartado 2, letra e). Esta interpretación responde también a la finalidad del RES, mencionada en su considerando 7, que consiste en facilitar el buen funcionamiento del mercado interior suprimiendo los obstáculos a la libre circulación de aquellas personas que desean ejercer sus derechos derivados de una sucesión de carácter transfronterizo. Según este mismo considerando, en el espacio europeo de justicia resulta imperativo que los ciudadanos puedan organizar su sucesión.

En este contexto, y a juicio del TJUE, admitir que el artículo 1, apartado 2, letra 1) del RES permite excluir del ámbito de aplicación de dicho Reglamento la adquisición de la propiedad de un bien mediante legado vindicatorio supondría una fragmentación de la sucesión incompatible con el tenor del artículo 23 del RES y con los objetivos de éste. Por consiguiente, concluye, "el artículo 1, apartado 2, letra 1) del RES debe interpretarse en el sentido de que se opone a la denegación del reconocimiento, en un Estado miembro cuyo ordenamiento jurídico no reconoce la institución del legado vindicatorio, de los efectos reales producidos por dicho legado en la fecha de apertura de la sucesión con arreglo a la ley sucesoria que ha sido elegida" (apartado 58 de la sentencia).

Como dato adicional e íntimamente conectado con este último pronunciamiento, debe destacarse la alusión que hace el Abogado General en su escrito de conclusiones al 
Reino de los Países Bajos, cuyo Derecho de sucesiones tampoco prevé el legado vindicatorio, y que ha procedido a adaptar sus disposiciones en materia de registro con ocasión de la transposición del RES, de forma que pasa a permitir al legatario vindicatorio inscribir su derecho de propiedad sobre la base del certificado sucesorio europeo que dé fe de que el legatario ha adquirido el bien inmueble mediante legado ${ }^{14}$.

\section{Reconocimiento y adaptación de derechos reales desconocidos a derechos reales equivalentes en su funcionalidad}

Se trata de una cuestión expuesta de forma somera en el apartado anterior, pero que requiere de un tratamiento separado en el marco del presente trabajo. Efectivamente, se ha hecho referencia al artículo 31 del RES, que lleva por rúbrica "adaptación de los derechos reales", así como a que, según el TJUE, en el supuesto que constituye el objeto de la sentencia que nos ocupa, "no es preciso llevar a cabo la adaptación prevista" en el artículo citado (apartado 64), concluyendo que dicho precepto debe ser interpretado "en el sentido de que se opone a la denegación del reconocimiento, en un Estado miembro cuyo ordenamiento jurídico no reconoce la institución del legado vindicatorio, de los efectos reales producidos por tal legado en la fecha de apertura de la sucesión con arreglo a la ley sucesoria que ha sido elegida" (apartado 65).

$\mathrm{Y}$ es que para permitir que los beneficiarios puedan disfrutar en otro Estado miembro de los derechos que hayan sido creados o les hayan sido transmitidos mediante sucesión (se entiende, con arreglo a la ley que la rija), el RES prevé la adaptación de un derecho real "desconocido" al derecho real equivalente más cercano del Derecho de ese otro Estado miembro. En el contexto de esa adaptación, se deben tener en cuenta los objetivos y los intereses que persiga el derecho real de que se trate y sus efectos.

Con la finalidad de determinar el derecho real equivalente más cercano del Derecho nacional, el RES ofrece la opción de poder entrar en contacto con las autoridades o personas competentes del Estado cuya ley se haya aplicado a la sucesión con la finalidad de obtener más información sobre la naturaleza y los efectos de ese

\footnotetext{
${ }^{14}$ Véase el artículo 27,a) de la Kadasterwet (Ley sobre el registro de la propiedad), de 3 de febrero de 2005, introducido en virtud del artículo 13 de la Uitvoeringswet Verordening erfrecht (Ley por la que se transpone el RES), de 5 de noviembre de 2014.
} 
derecho. A estos efectos, podría recurrirse a las redes existentes en el ámbito de la cooperación judicial en materia civil y mercantil, así como a cualquiera otros medios disponibles que faciliten la comprensión de la ley extranjera (considerando 16 del RES).

La adaptación de derechos reales desconocidos explícitamente contemplada en el RES no debe excluir otras formas de adaptación en el contexto de la aplicación del propio Reglamento (considerando 17).

A la vista de lo expuesto, podríamos señalar que la adaptación de los derechos reales presenta los siguientes condicionantes:

- Que medie necesidad y, en todo caso, que sea posible. En este sentido, se deben tener en cuenta los objetivos y los intereses que persiga el derecho real de que se trate y sus efectos.

- Que exista en el Derecho del Estado miembro en el que se invoque el derecho real desconocido otro derecho real que resulte equivalente. A fin de determinar el derecho real equivalente más cercano del Derecho nacional, se podrá entrar en contacto con las autoridades o personas competentes del Estado cuya ley se haya aplicado a la sucesión para obtener más información sobre la naturaleza y los efectos de ese derecho.

En el marco del Derecho interno español, la doctrina del numerus apertus en la configuración de los derechos reales (artículos 2 de la Ley Hipotecaria y 7 de su Reglamento), facilita la aplicación práctica de la técnica de la adaptación de derechos reales desconocidos en nuestro sistema, como derechos atípicos o innominados. El problema se plantea con mayor gravedad en aquellos países que se rigen por un estricto sistema de numerus clausus. Y es que en ellos, la circulación de la riqueza inmobiliaria o el tráfico jurídico-inmobiliario resulta incompatible con el reconocimiento de categorías de derechos reales no conocidos en el Derecho interno (un claro ejemplo lo vemos en el supuesto de la sentencia con los legados reales, desconocidos en Alemania, donde, como ya se ha dicho, tienen carácter obligacional) ${ }^{15}$.

\footnotetext{
${ }^{15}$ Pero incluso en el caso de los países que admiten la doctrina del numerus apertus existen límites que no se pueden sobrepasar, y que no siempre se encuentran definidos con total claridad. Así, según DÍAZ FRAILE, J.M. "El Reglamento Sucesorio Europeo: El principio de adaptación de los derechos reales y los límites impuestos por la lex rei sitae. Especial referencia al certificado sucesorio". Revista Crítica de
} 
En cualquier caso, debe valorarse positivamente la introducción de la figura de la adaptación, en cuanto procura soluciones lógicas en el campo de los derechos reales en la relación entre el mercado interior y la comunidad de derecho europea, de un lado, y la autonomía interna de la organización de la propiedad, del otro. Adicionalmente, puede observarse cómo esta técnica también fue incorporada por el Reglamento (UE) 1215/2012, del Parlamento Europeo y del Consejo, de 12 de diciembre de 2012, relativo a la competencia judicial, el reconocimiento y la ejecución de resoluciones judiciales en materia civil y mercantil ${ }^{16}$, cuyo artículo 54.1 dispone que "si una resolución contiene una medida o una orden que no es conocida en el ordenamiento jurídico del Estado miembro requerido, la medida o la orden se adaptará, en lo posible, a una medida u orden conocida en el ordenamiento jurídico de dicho Estado miembro que tenga efectos equivalentes y persiga una finalidad e intereses similares, Dicha adaptación no tendrá más efectos que los dispuestos en el Derecho del Estado miembro de origen".

\footnotetext{
Derecho Inmobiliario, enero-febrero 2014, núm. 741, pp. 67-111, en el caso del Ordenamiento Jurídico español la posible recepción de derechos reales desconocidos por el sistema interno y previsto en la ley sucesoria admite en la actualidad diversas modalidades graduadas de mayor a menor en cuatro niveles que van desde la aceptación al rechazo, pasando por la adaptación y la limitación. En este sentido, y según el autor, en el supuesto de aceptación no hay propiamente operación alguna de adaptación, pues es posible incorporar al Ordenamiento interno el derecho real extranjero nominalmente desconocido sin alteración material alguna al adaptarse su contenido a la configuración estructural de los derechos reales del Derecho interno; en el caso de la adaptación, se parte del contenido de los artículos 2.2 de la Ley Hipotecaria y 7 del Reglamento Hipotecario, que permiten la constitución de nuevas figuras de derechos reales no específicamente previstas por el legislador, con la posibilidad de alteración del contenido típico de los derechos reales legalmente previstos, con el deber de ajustarse a determinados límites y de respetar las normas estructurales del estatuto jurídico de los bienes, dado su significado económico-político y la trascendencia erga omnes de los derechos reales; también nos encontraríamos con supuestos de limitación, donde si bien el derecho real extranjero es admisible en el Ordenamiento interno, éste impone limitaciones a la extensión del derecho desconocidas en el Ordenamiento extranjero bajo cuya legislación se constituyó (y cita, a título de ejemplo, las sustituciones fideicomisarias o ciertos usufructos en el caso español, que no pueden constituirse más allá del límite de la segunda generación a fin de evitar la amortización de la propiedad, ni constituirse, en el caso de los usufructos, por un plazo superior a treinta años); y finalmente nos podríamos encontrar con supuestos de rechazo, al no ser viable la aplicación técnica de la adaptación, en aquellos casos en que sea de aplicación la excepción del orden público o exista un régimen imperativo o normas de derecho cogente que impiden la inscripción de los derechos reales tal y como se conocen en el derecho extranjero.

${ }^{16}$ DOUE L 351/1, de 20 de diciembre de 2012.
} 


\section{III.- CERTIFICADO SUCESORIO EUROPEO Y REGISTRO DE LA PROPIEDAD}

\section{Breve aproximación al concepto de certificado sucesorio europeo}

Tal y como señala la Sentencia del TJUE objeto de estudio, el RES establece la creación de un certificado que debe permitir a cada heredero, legatario o derechohabiente mencionado en el mismo acreditar en otro Estado miembro su cualidad y sus derechos, en particular la atribución de un bien concreto al legatario mencionado en dicho certificado (apartado 59). Así, en virtud del artículo 69.1 del RES, el certificado surtirá sus efectos en todos los Estados miembros sin necesidad de ningún pronunciamiento especial. El apartado 2 de ese mismo artículo dispone que se presumirá que la persona que figura en el certificado como legatario tiene la cualidad y los derechos indicados en él sin más condiciones o limitaciones que las mencionadas en el certificado (apartado 60).

De conformidad con el considerando 67 del RES, la tramitación rápida, ágil y eficiente de las sucesiones con repercusión transfronteriza en la UE requiere que los herederos, legatarios, ejecutores testamentarios o administradores de la herencia puedan probar fácilmente su cualidad como tales o sus derechos o facultades en otro Estado miembro, por ejemplo en el Estado miembro en que estén situados los bienes sucesorios. Para que lo puedan hacer, dicho Reglamento debe prever la creación de un certificado uniforme, el certificado sucesorio europeo (en adelante, CSE) que se expedirá para su uso en otro Estado miembro. Conforme al principio de subsidiariedad, el CSE no debe sustituir a los documentos que puedan existir con efectos similares en los Estados miembros ${ }^{17}$.

Para la creación del CSE, se parte de una premisa irrefutable, cual es que en el marco del Derecho comparado europeo las soluciones en relación con la atribución de

\footnotetext{
${ }^{17}$ Se cumple así con el principio de subsidiariedad imperante en el Derecho comunitario, por ello el artículo 62.3 del RES dispone que "el certificado no sustituirá a los documentos internos empleados en los Estados miembros para fines similares. No obstante, una vez expedido para ser utilizado en otro Estado miembro, el certificado producirá igualmente los efectos enumerados en el artículo 69 en el Estado miembro cuyas autoridades lo hayan expedido con arreglo a lo dispuesto en el presente capítulo". A juicio de GIMENO GÓMEZ-LAFUENTE, J.L. "El certificado sucesorio europeo". Revista Crítica de Derecho Inmobiliario, enero-febrero 2014, núm. 741, pp. 113 a 151, si bien se salva el principio de subsidiariedad, el último inciso del precepto admite la validez interna del CSE, lo cual puede plantear dificultades cuando exista contradicción entre dicho certificado y el que se expida en el ámbito local, o la figura similar correspondiente (a título de ejemplo, un acta de declaración de herederos).
} 
efectos extraterritoriales a los documentos relativos a las sucesiones hereditarias en supuestos internacionales son ciertamente diversas, y van desde sistemas abiertos y permisivos, hasta otros en los que se impone la atribución de competencias exclusivas a las autoridades del foro, admitiendo tan sólo los documentos de producción interna en caso de que la sucesión afecte a bienes inmuebles.

Con la finalidad de solucionar los problemas prácticos derivados de esta diversidad en el ámbito de la UE, se incorpora al RES este novedoso título sucesorio específico, cuyo objeto es el de acreditar la condición de heredero, legatario, ejecutor o administrador de la herencia con vigencia en toda la UE. En este sentido, dispone el artículo 63.1 del RES que "el certificado se expedirá para ser utilizado por los herederos, legatarios que tengan derechos directos en la herencia y ejecutores testamentarios o administradores de la herencia que necesiten invocar, en otro Estado miembro, su cualidad de tales o ejercer sus derechos como herederos o legatarios, o bien sus facultades como ejecutores testamentarios o administradores de la herencia". Ahora bien, de conformidad con el apartado 2 del artículo 62 del RES, "la utilización del certificado no será obligatoria", y el mismo "no sustituirá a los documentos internos empleados en los Estados miembros para fines similares" (apartado 3 de dicho precepto).

\section{El certificado sucesorio europeo como título inscribible en el Registro de la}

\section{Propiedad español}

Debemos partir del artículo 69.1 del RES, que con carácter general establece que el CSE "surtirá sus efectos en todos los Estados miembros sin necesidad de ningún procedimiento especial". En particular, y para el caso de la eventual inscripción de la adquisición hereditaria en un registro público (y en el caso español, en el Registro de la Propiedad), el apartado 5 de dicho artículo considera que el CSE "será un título válido para la inscripción, sin perjuicio de lo dispuesto en el artículo 1, apartado 2, letras k) y 1)". Como hemos visto, este último inciso se refiere a la exclusión del ámbito del RES de las cuestiones concernientes a la naturaleza de los derechos reales y de todo lo relativo a las inscripciones de derechos sobre bienes muebles o inmuebles en un Registro, incluidos los requisitos legales para la práctica de los asientos y los efectos de la inscripción o de la omisión de la inscripción de tales derechos en el mismo. 
En consecuencia, como ya se ha apuntado a lo largo de este trabajo, la cuestión relativa a la calificación, inscripción y a los requisitos legales para la práctica de los asientos registrales, así como a los efectos de los mismos, queda referida a la competencia propia de los Estados en su ámbito respectivo ${ }^{18}$.

Sentado lo anterior, nuestra legislación hipotecaria se ha adaptado a las previsiones del RES respecto del CSE, y así, el artículo 14.1 de la Ley Hipotecaria ${ }^{19}$ pasa a incorporar dicho CSE al repertorio de títulos sucesorios, tras sendas reformas operadas en virtud de la Disposición final duodécima de la Ley 15/2015, de 2 de julio, de la Jurisdicción Voluntaria, y por la Disposición final primera de la Ley 29/2015, de 30 de julio, de cooperación jurídica internacional en materia civil.

Dada la condición de título inscribible del CSE, el considerando 68 del RES impone a la autoridad emisora el deber de tener en cuenta las "formalidades" que se exigen para la inscripción de bienes inmuebles en el Estado miembro en el que esté situado el Registro, y a tal efecto prevé el intercambio de información sobre tales "formalidades". A la hora de precisar el alcance del término "formalidades" que utiliza el citado considerando 68 no se debe olvidar que el mismo no puede limitar ni condicionar desde su significado usual la naturaleza de la totalidad de los requisitos exigidos para la inscripción registral por la legislación específicamente aplicable del Estado miembro en el que esté situado el registro ${ }^{20}$.

\footnotetext{
${ }^{18}$ Viene a coincidir esta solución del RES con la norma interna española. Y es que el artículo 58 de la Ley 29/2015, de 30 de julio, de Cooperación Jurídica Internacional en materia civil, establece que "el procedimiento registral, los requisitos legales y los efectos de los asientos registrales se someterán, en todo caso, a las normas del Derecho español".

${ }^{19}$ De conformidad con esta nueva redacción del artículo 14.1 LH, "El título de la sucesión hereditaria, a los efectos del Registro, es el testamento, el contrato sucesorio, el acta de notoriedad para la declaración de herederos abintestato y la declaración administrativa de heredero abintestato a favor del Estado, así como, en su caso, el certificado sucesorio europeo al que se refiere el capítulo VI del Reglamento (UE) n. ${ }^{\circ} 650 / 2012 "$.

${ }^{20}$ DOMÍNGUEZ CALATAYUD, V. "Efectos del certificado sucesorio europeo: examen particular del certificado como título inscribible en el Registro de la propiedad español. Una pretendida armonización entre los efectos protectores de uno y otro". Bitácora Millennium, n², septiembre 2016, Zaragoza.
} 


\section{Control registral: A) Calificación. B) Inscripción registral. C) Efectos.}

\section{A) Calificación}

Debe tenerse presente en este ámbito el contenido del considerando 18 del RES, al que ya he aludido en este trabajo, y en cuya virtud los requisitos de la inscripción en un registro de un derecho sobre bienes (en este caso) inmuebles se deben excluir del ámbito de aplicación del RES. En consecuencia, debe ser el Derecho del Estado miembro en que esté situado el registro (que para el caso de los bienes inmuebles, será el correspondiente al lugar de su ubicación) el que determine en qué condiciones legales y de qué manera se realiza la inscripción, así como qué autoridades, como registradores de la propiedad o notarios, deben ocuparse de verificar (calificar) que se reúnen todos los requisitos y que la documentación presentada es suficiente o contiene la información necesaria.

En particular, precisa dicho considerando, "las autoridades podrán comprobar que el derecho del causante sobre los bienes sucesorios mencionados en el documento presentado para su inscripción es un derecho inscrito como tal en el registro", lo que hace alusión al principio hipotecario español de tracto sucesivo ${ }^{21}$.

Desde un punto de vista formal, y con la finalidad de evitar la duplicidad de documentos, las autoridades del registro deben aceptar los documentos expedidos por las autoridades competentes de otro Estado miembro cuya circulación se contempla en el RES. Y esto nos lleva al CSE expedido en virtud del RES, que como se ha dicho "debe constituir un documento válido para inscribir los bienes sucesorios en el registro de un Estado miembro" ${ }^{22}$. Ahora bien, esto no puede impedir que las autoridades que tramiten la inscripción (en nuestro caso, los Registradores de la Propiedad) puedan pedir

${ }^{21}$ El principio hipotecario de tracto sucesivo se encuentra recogido por el artículo 20 de la Ley Hipotecaria, que en su apartado primero establece que "para inscribir o anotar títulos por los que se declaren, transmitan, graven, modifiquen o extingan el dominio y demás derechos reales sobre inmuebles, deberá constar previamente inscrito o anotado el derecho de la persona que otorgue o en cuyo nombre sean otorgados los actos referidos".

${ }^{22}$ En opinión de DÍAZ FRAILE, J.M. "El Reglamento Sucesorio Europeo: El principio de adaptación de los derechos reales..." Op. Cit., "del mismo modo, en el caso español algunos de los requisitos impuestos por la normativa registral, como la exigencia de obtener el reconocimiento a título principal de una resolución judicial en materia sucesoria proveniente de otro Estado comunitario, o la exigencia de legalización o apostilla deben quedar descartadas en los supuestos incluidos dentro del ámbito de aplicación del Reglamento (cfr. artículos 4 de la Ley Hipotecaria y 36 de su Reglamento). 
a la persona que la solicita que presente la información o los documentos adicionales requeridos en virtud de la ley del Estado miembro en el que esté situado el registro ${ }^{23}$, pudiendo, en su caso, indicar a la persona que solicita la práctica del asiento cómo puede proporcionar la información o los documentos que falten.

A la vista de lo expuesto, y ya en el marco de la estricta calificación por parte del Registrador de la Propiedad del CSE, resulta interesante plantearse ante qué tipo de documento nos encontramos: judicial, notarial, o bien un documento único no asimilable a ninguna de las categorías citadas ${ }^{24}$. Y ello con fundamento en el contenido del considerando 70 del RES, según el cual "el certificado se debe expedir en el Estado miembro cuyos tribunales sean competentes en virtud del presente Reglamento. Debe corresponder a cada Estado miembro determinar en su legislación interna qué autoridades serán competentes para expedir el certificado, ya sean tribunales tal como se definen a efectos del presente Reglamento, ya sean otras autoridades con competencias en asuntos sucesorios, como por ejemplo los notarios".

El artículo 59 de la Ley 29/2015, antes citada, se refiere a la inscripción de resoluciones judiciales extranjeras y establece, con carácter previo a la calificación, que se llevará a cabo con la misma amplitud prevista para las resoluciones judiciales españolas conforme a los artículos 18 de la Ley Hipotecaria, y 98 y 100 de su Reglamento ${ }^{25}$.

\footnotetext{
${ }^{23}$ De acuerdo con la Resolución de la Dirección General de los Registros y del Notariado, de fecha 10 de abril de 2017, "en cuanto no se complete la interconexión de los Registros de disposiciones sucesorias y de certificados sucesorios europeos de los Estados miembros, medida complementaria a la aplicación del RES en el contexto e-justice, parece sólo oportuno mantener la exigencia de la acreditación de la obtención de certificación diferente al de nuestro Registro General de Actos de Última Voluntad, que acreditare la existencia o no de disposición de última voluntad cuando de la valoración de los elementos concurrentes en la sucesión resultare que la ley aplicable fuere distinta de la española, imponiéndose la presentación de certificado o justificación de su inexistencia en el Estado cuya ley resultare aplicable a la sucesión o a la disposición de última voluntad (artículos 21, 22, 24 y 25 del RES), sea o no la del Estado o Estados cuya nacionalidad ostentare el causante".

${ }^{24}$ Sobre este particular, vid. RODRÍGUEZ SÁNCHEZ, J.S. "Una introducción al Reglamento de Sucesiones de la UE...". Op. Cit. p. 232. En opinión de DÍAZ FRAILE, J.M. "El Reglamento Sucesorio Europeo: El principio de adaptación de los derechos reales y los límites impuestos por la lex rei sitae (...)". Op. cit., en realidad, dentro de la citada atipicidad, se trata de una figura más próxima al documento público que a la resolución judicial, como lo evidencia el carácter revisable de su contenido, su validez temporalmente limitada y, desde luego, la ausencia total de efecto de cosa juzgada (artículos 71, 72 y 73 del RES).

${ }^{25}$ De conformidad con el apartado 2 de dicho precepto, "para la inscripción de las resoluciones judiciales extranjeras a que se refiere el apartado anterior, con carácter previo a la calificación del título inscribible, el registrador verificará la regularidad y la autenticidad formal de los documentos presentados y la inexistencia de las causas de denegación de reconocimiento previstas en el capítulo II del presente título, debiendo notificar su decisión, por correo, telegrama o cualquier otro medio técnico que permita dejar constancia de la recepción, de su fecha y del contenido de lo comunicado al presentante y a la parte frente
} 
Por su parte, el artículo 60 de la Ley 29/2015 se refiere a la inscripción de los documentos públicos extranjeros extrajudiciales, sean notariales o no, que podrán ser inscritos en los registros públicos españoles si cumplen los requisitos establecidos en la legislación específica aplicable y siempre que la autoridad extranjera haya intervenido en la confección del documento desarrollando funciones equivalentes a las que desempeñan las autoridades españolas en la materia de que se trate y surta los mismos o más próximos efectos en el país de origen. El ámbito de la función calificadora será el mismo previsto en la legislación hipotecaria española para el documento notarial, esto es, artículos 18 de la Ley Hipotecaria y 98 de su Reglamento ${ }^{26}$.

\section{B) Inscripción registral}

La inscripción de bienes concretos a favor de los herederos requerirá como regla general el correspondiente documento particional o de entrega de bienes, normalmente escritura pública ${ }^{27}$. En caso de heredero único, en relación con ciertas situaciones particulares que permita la ley aplicable, sería posible considerar la inscripción de bienes concretos en base al contenido del $\mathrm{CSE}^{28}$.

DOMÍNGUEZ CALATAYUD ${ }^{29}$ entiende que el CSE será título directamente inscribible en el Registro de la Propiedad español en algunos casos, y en otros no lo será si no se acompaña de los documentos de Derecho civil necesarios para entender consumado por el heredero o legatario el proceso adquisitivo. Así, procederá la inscripción directa del CSE en supuestos en los que conforme a la ley aplicable a la sucesión se adquieran cuotas por los herederos en relación con todos y cada uno de los bienes hereditarios; en los supuestos de heredero único; en el supuesto de legados de

a la que se pretende hacer valer la resolución extranjera, en el domicilio que conste en el Registro o en la resolución presentada (...)".

${ }^{26}$ Según este precepto, "los documentos públicos extranjeros extrajudiciales podrán ser inscritos en los registros públicos españoles si cumplen los requisitos establecidos en la legislación específica aplicable y siempre que la autoridad extranjera haya intervenido en la confección del documento desarrollando funciones equivalentes a las que desempeñan las autoridades españolas en la materia de que se trate y surta los mismos o más próximos efectos en el país de origen".

${ }^{27}$ MARTÍN ROMERO, C. "El certificado sucesorio europeo: propuesta reglamentaria". El notario del siglo XXI, 2010, núm. 31, pp. 6-7.

${ }^{28}$ RODRÍGUEZ SÁNCHEZ, J.S. "Una introducción al Reglamento de Sucesiones de la UE...". Op. Cit. p. 261.

${ }_{29}$ DOMÍNGUEZ CALATAYUD, V. "Efectos del certificado sucesorio europeo: examen particular del certificado ...", Op. Cit. pp. 10 y 11. 
cosa que se adquieran automáticamente por el legatario desde la muerte del causante según la ley sucesoria; en el supuesto de pactos sucesorios en que consten incorporados al certificado todos los datos necesarios para la práctica de la inscripción o en los casos de un testamento directamente particional válido según la ley sucesoria.

Fuera de estos casos, y según el citado autor, el CSE deberá ir acompañado de los otros títulos sucesorios recogidos en el artículo 14.1 de la Ley Hipotecaria, del correspondiente documento de adjudicación de los bienes hereditarios, sea una partición judicial, sea una partición notarial que haga a los herederos o legatarios dueños de bienes concretos de la herencia o de partes indivisas de ellos según la ley sucesoria que será aplicada por el registrador de la propiedad español en ejercicio de su función calificadora.

\section{C) Efectos}

En cuanto a los efectos de la inscripción registral, el considerando 19 se expresa con claridad, precisando que "se deben excluir también del ámbito de aplicación del presente Reglamento los efectos de la inscripción de los derechos en el registro. En consecuencia, debe corresponder al Derecho del Estado miembro en que esté situado el registro determinar si la inscripción tiene, por ejemplo, efecto declarativo o constitutivo. Así pues, en caso de que, por ejemplo, la adquisición de un derecho sobre un bien inmueble deba ser inscrita con arreglo al Derecho del Estado miembro en que esté situado el registro para producir efectos erga omnes o para la protección legal del negocio jurídico, el momento de dicha adquisición deberá regirse por el Derecho de ese Estado miembro".

Íntimamente ligada a esta cuestión se encuentra la posibilidad, derivada de la cohabitación del CSE con otros títulos sucesorios, de contradicción entre los mismos, pudiendo darse también el caso de contradicción entre distintos $\mathrm{CSE}^{30}$. Se trata de una

\footnotetext{
30 Sobre esta particularidad, vid. DÍAZ FRAILE, J.M. "El certificado sucesorio europeo. Especial referencia a sus efectos y a su condición de título inscribible en el Registro de la Propiedad". Boletín del Colegio de Registradores, núm. 31, julio 2016, pp. 749-763. El autor se refiere de forma específica a lo que denomina "coexistencia con los títulos sucesorios nacionales" (pp. 752 y 753), apuntando que "otro elemento característico del CSE es que no se configura con el carácter de documento excluyente de los títulos sucesorios nacionales o internos previstos por las leyes de cada Estado, con los que, por lo tanto, puede coexistir". Ahora bien, "la citada configuración no excluyente del CSE y su posible coexistencia con los títulos sucesorios internos de cada país, puede derivar en un problema de contradicción entre el
} 
cuestión prevista en el considerando 66 del RES en los siguientes términos: La autoridad a la que, en el contexto de aplicación del presente Reglamento, se le presenten dos documentos públicos incompatibles debe evaluar a qué documento público ha de dar prioridad, si ha de dar prioridad a alguno, teniendo en cuenta las circunstancias del caso concreto. En caso de que de esas circunstancias no se desprenda de manera clara a qué documento público se ha de dar prioridad, si se ha de dar prioridad a alguno, la cuestión debe ser resuelta por los tribunales que sean competentes en virtud del presente Reglamento, o, en caso de que la cuestión se plantee como cuestión incidental en el transcurso del procedimiento, por el tribunal ante el que se haya iniciado el procedimiento. En caso de incompatibilidad entre un documento público y una resolución, deben tomarse en consideración los motivos para denegar el reconocimiento de resoluciones en virtud del presente Reglamento.

Ante esta eventualidad, la doctrina ${ }^{31}$ coincide en afirmar que, ante la ausencia de un registro europeo de certificados sucesorios -idóneo para resolver, a semejanza por ejemplo del Registro General de Actos de última voluntad español, aquellos supuestos de contradicción-, debería considerarse plenamente vigente en nuestro Derecho el artículo 28 de la Ley Hipotecaria, conforme al cual "las inscripciones de fincas o derechos reales adquiridos por herencia o legado, no surtirán efecto en cuanto a tercero hasta transcurridos dos años desde la fecha de la muerte del causante. Exceptúanse las inscripciones por título de herencia testada o intestada, mejora o legado a favor de herederos forzosos", de forma que frente al adquirente del heredero aparente, el heredero real mantendrá sus acciones civiles derivadas de la hereditatis petitio, de forma que solo tras el transcurso de ese plazo de dos años el tercero hipotecario del artículo 34 de la Ley Hipotecaria quedaría protegido por el carácter a non domino de su adquisición.

CSE y el título interno (ya se trate de una resolución judicial o de un documento público extrajudicial), problema que se agrava dado que la amplia definición de las reglas sobre competencia de autoridades puede suponer no sólo la coexistencia entre el título europeo y el nacional, sino también la posible existencia de más de un CSE, multiplicando el riesgo de incoherencias o contradicciones de los mismos". 31 Vid. GIMENO GÓMEZ-LAFUENTE, J.L. "El certificado sucesorio europeo". Op. Cit., quien concluye que "no habría estado de más que en un sistema como el vigente en los Estados miembros sin un registro general de actos de última voluntad fiable, y hasta tanto se consolide un registro europeo de testamentos, se hubiera adoptado en el reglamento un periodo de vacancia similar al español en protección del heredero aparente (artículo 28.1 de la Ley Hipotecaria)". 


\section{IV.- CONCLUSIONES}

Tales son:

- El 17 de agosto de 2015 marcó el inicio de la aplicabilidad del Reglamento (UE) $N^{o}$ 650/2012 del Parlamento Europeo y del Consejo de 4 de julio de 2012, relativo a la competencia, la ley aplicable, el reconocimiento y la ejecución de las resoluciones, a la aceptación y la ejecución de los documentos públicos en materia de sucesiones mortis causa y a la creación de un certificado sucesorio europeo.

- Dicho Reglamento tiene por objetivo el mantener y desarrollar un espacio de libertad, de seguridad y de justicia, mediante la adopción gradual de medidas dirigidas a la cooperación judicial en asuntos civiles con repercusión transfronteriza, suprimiendo obstáculos a la libre circulación de personas, en particular en aquellos casos en que sea necesario para el buen funcionamiento del mercado interior.

- La regulación contenida en el RES en el ámbito de la ley aplicable se asienta sobre la base de dos principios fundamentales: de un lado, el de aplicación universal, en cuya virtud la ley se aplicará aún cuando no sea la de un estado miembro; y el de unidad de la sucesión, en virtud del cual habrá una sola ley aplicable a la sucesión, con independencia de la naturaleza de los bienes y del lugar donde se hallen.

- Cuando nos referimos al ámbito de aplicación del RES, lo hacemos desde una óptica triple: espacial, temporal y material, incidiendo, a los efectos del presente trabajo, en este último ámbito. El artículo 1 del RES se refiere expresamente al ámbito de aplicación material del mismo, estructurándose en torno a dos apartados: según el apartado 1 de dicho artículo, el RES se aplicará a las sucesiones por causa de muerte, y no será aplicable a las cuestiones fiscales, aduaneras y administrativas; por su parte, el apartado 2 contiene una enumeración de materias que expresamente quedan fuera del ámbito de su ámbito de aplicación. 
- En lo que resulta de interés a los efectos del trabajo propuesto, me he centrado en los supuestos de exclusión previstos en las letras k) y 1) del artículo 1.2 del RES, es decir: "k) naturaleza de los derechos reales" y "l) cualquier inscripción de derechos sobre bienes muebles o inmuebles en un registro, incluidos los requisitos legales para la práctica de los asientos, y los efectos de la inscripción o de la omisión de inscripción de tales derechos en el mismo".

- La sentencia del TJUE (Sala Segunda), de 12 de octubre de 2017, asunto C218/16, Aleksandra Kubicka, constituye el primer pronunciamiento interpretativo del RES por parte de dicho Tribunal. El supuesto de la resolución es el otorgamiento de testamento por parte de la señora Kubicka, de nacionalidad polaca y residente en Alemania, que se dirige a un notario de Polonia para instituir herederos a su esposo y a sus hijos por iguales partes, disponiendo además un legado vindicatorio (permitido por el Derecho polaco, pero que resulta contrario a la legislación y jurisprudencia alemanas en materia de derechos reales y del Registro de la Propiedad) a favor de su marido, sobre su participación en un terreno sobre el que se encuentra construida su vivienda familiar, sita en Alemania. Y es que en Alemania, los legados vindicatorios extranjeros son objeto de una adaptación, con arreglo al artículo 31 del RES, y pasan a ser legados damnatarios u obligacionales.

- La cuestión central que se trata de dirimir ante el TJUE en este caso consiste en determinar el sentido y alcance de la exclusión material prevista en el RES en sus considerandos 15, 18 y 19, así como en su artículo 1, apartado 2, letras k) y 1), y en su artículo 31, relativo a la naturaleza de los derechos reales, así como a los requisitos legales y efectos de su inscripción (o de la falta de inscripción) en un registro. Dicha cuestión debe proyectarse hacia la propia esencia de la previsión contenida en el artículo 23.1 del RES, en este caso delimitada en si el legado de un derecho real (propiedad) que el Estado miembro del lugar de situación del inmueble conoce, debe producir sus efectos respecto del legatario, con independencia del lugar en el que deba ser registrado, puesto que dicho derecho sobre el bien inmueble le ha sido 
transmitido directamente en virtud de la ley sucesoria (polaca) designada conforme al artículo 22 del RES.

- El TJUE reconoce que "en el presente asunto, tanto el legado vindicatorio, previsto por el Derecho polaco, como el legado damnatorio u obligacional, previsto por el Derecho alemán, constituyen modalidades de transmisión de la propiedad de un bien, esto es, un derecho real reconocido en los dos sistemas jurídicos afectados. De este modo, la transmisión directa de un derecho de propiedad mediante un legado vindicatorio sólo afecta a las modalidades de transmisión de ese derecho real al fallecer el testador, transmisión que, según su considerando 15, justamente el RES permite de conformidad con la ley aplicable a la sucesión" (apartado 49). Para concluir que, "tales modalidades de transmisión no están comprendidas" en el ámbito de aquella exclusión. Por consiguiente, a juicio del TJUE, "ha de considerarse que el artículo 1, apartado 2, letra k) del RES debe interpretarse en el sentido de que se opone a la denegación del reconocimiento, en Estado miembro cuyo ordenamiento jurídico no reconoce la institución del legado vindicatorio, de los efectos reales producidos por dicho legado en la fecha de apertura de la sucesión con arreglo a la ley sucesoria elegida por el testador" (apartado 51). Y es que resulta evidente, en definitiva, que la naturaleza del derecho real (que es el de propiedad) no se discute, ya que tal derecho se encuentra reconocido por los dos sistemas jurídicos afectados. En consecuencia, no opera la exclusión invocada.

- De otro lado, el TJUE considera que a la vista del contenido de los considerandos 18 y 19 del RES, puesto que el artículo 1, apartado 2, letra 1) del RES sólo se refiere a la inscripción de derechos sobre bienes muebles o inmuebles en un registro, incluidos los requisitos legales para la práctica de los asientos, y a los efectos de la inscripción o de la omisión de inscripción de tales derechos en el mismo, los requisitos para la adquisición de tales derechos no figuran entre las materias excluidas del ámbito de aplicación de dicho Reglamento en virtud de la citada disposición" (apartado 54 de la sentencia). Dicha interpretación aparece confirmada por el principio de 
unidad de la ley sucesoria, previsto en el artículo 23 del RES, y especialmente en su apartado 2, letra e).

- Entre las novedades más destacables del RES, si bien su utilización no es obligatoria, se encuentra la creación del denominado CSE como "certificado uniforme" que debe tener fuerza probatoria (artículo 62.2 y Considerando 67 del RES).

- El CSE no requiere ser un título con fuerza ejecutiva por sí mismo y, además, no debe sustituir a los documentos que puedan existir con efectos similares en los Estados miembros; es decir, en España seguirá funcionando perfectamente la escritura de aceptación y partición de herencia. Cuestión distinta es que conforme al RES pueda ser inscribible en el Registro de la Propiedad español el CSE procedente de otro país, sin perjuicio de que para cumplir con nuestra legislación hipotecaria se le puedan exigir determinadas cautelas (en forma de documentación o información adicional).

- El CSE podrá ser expedido tanto por la autoridad judicial como por un notario. El original lo debe conservar la autoridad que lo expida, que deberá facilitar copias auténticas del mismo a las personas que demuestren interés legítimo.

- Nuestra legislación hipotecaria se ha adaptado a las previsiones del RES respecto del CSE, y así, el artículo 14.1 de la Ley Hipotecaria pasa a incorporar dicho CSE al repertorio de títulos sucesorios, tras sendas reformas operadas en virtud de la Disposición final duodécima de la Ley 15/2015, de 2 de julio, de la Jurisdicción Voluntaria, y por la Disposición final primera de la Ley 29/2015, de 30 de julio, de cooperación jurídica internacional en materia civil.

- Suele afirmarse que los efectos del CSE son los mismos que derivan del artículo 34 de la Ley Hipotecaria. Sin embargo, dicha afirmación debe matizarse: a) porque el CSE solo actúa frente a adquisiciones hereditarias de bienes concretos que figuran en el mismo; b) porque admite prueba en contrario; y c) porque el CSE no otorga ninguna presunción sobre la 


\section{Revista Internacional de \\ Doctrina y Jurisprudencia}

efectividad de las cláusulas que se hacen constar, ya que únicamente excluye la presunción de que no existen.

- No habría estado de mas que en un sistema como el vigente en los Estados miembros sin un registro general de actos de última voluntad fiable, y hasta tanto se consolide un registro europeo de testamentos, se hubiera adoptado en el RES un periodo de vacancia similar al español en protección del heredero aparente. No obstante, la doctrina considera que, ante la ausencia de un registro europeo de certificados sucesorios, debe considerarse plenamente vigente en nuestro Derecho la previsión contenida en el artículo 28 de la Ley Hipotecaria. 


\section{BIBLIOGRAFÍA}

- Bonomi, A. y Wautelet, P. "Le droit européen des successions, Commentaire du Règlement (UE) $n^{o}$ 650/2012, du 4 juillet 2012". Bruylant, $2^{\mathrm{a}}$ edición, Bruselas, febrero 2016.

- Calvo Vidal, I. "El Derecho de sucesiones en la Unión Europea. Ley aplicable y carácter universal de la nueva normativa en materia de sucesiones". Noticias de la UE, núm. 328, 2012, pp. 97-107.

- Carrascosa González, J. "Reglamento sucesorio europeo y residencia habitual del causante". Cuadernos de Derecho Transnacional, marzo 2016, vol. 8, núm. 1, p. 54.

- Díaz Fraile, J. M. "El Reglamento Sucesorio Europeo: El principio de adaptación de los derechos reales y los límites impuestos por la lex rei sitae. Especial referencia al certificado sucesorio". Revista Crítica de Derecho Inmobiliario, enerofebrero 2014, núm. 741, pp. 67-111.

- Díaz Fraile, J. M. "El certificado sucesorio europeo. Especial referencia a sus efectos y a su condición de título inscribible en el Registro de la Propiedad". Boletín del Colegio de Registradores, núm. 31, julio 2016, pp. 749-763.

- Domínguez Calatayud, V. "Efectos del certificado sucesorio europeo: examen particular del certificado como título inscribible en el Registro de la propiedad español. Una pretendida armonización entre los efectos protectores de uno y otro". Bitácora Millennium, n², septiembre 2016, Zaragoza.

- Gimeno Gómez-Lafuente, J. L. "El certificado sucesorio europeo". Revista Crítica de Derecho Inmobiliario, enero-febrero 2014, núm. 741, pp. 113 a 151.

- Martín Romero, C. "El certificado sucesorio europeo: propuesta reglamentaria". El notario del siglo XXI, 2010, núm. 31.

- Puig Blanes, F. "Cuestiones esenciales que plantea en la práctica el Reglamento 650/2012 con especial referencia al Derecho Interregional", XXV Encuentros del Foro Aragonés, p. 147.

- Rodríguez Sánchez, J. S. "Una introducción al Reglamento de Sucesiones de la UE -desde la perspectiva de los derechos reales sobre bienes inmuebles y el Registro de la Propiedad en España-". Cuadernos de Derecho Registral, Colegio de Registradores de la Propiedad y Mercantiles de España, Madrid, 2013. 